\title{
RESEARCH
}

Open Access

\section{Identity evolution of STEM teachers in Egyptian STEM schools in a time of transition: a case study}

Mohamed El Nagdi* ${ }^{*}$ and Gillian Roehrig

\begin{abstract}
Background: The study was initiated as a response to the growing Science, Technology, Engineering, and Mathematics (STEM) experience in Egypt in terms of the growing number of schools, number of students admitted, and the effect of this experience on the overall education system in the country. Viewing teachers as the backbone of the STEM experience and teaching as a relational sociocultural practice (Biesta, G. \& Stengel, B. (2016) AREA Handbook of research on teaching, 5th edition), this research explores the evolution of teachers' STEM identity during their professional journey in the Egyptian STEM education reform initiative.

Aim: The purpose of this study is to explore the dynamic dialogical interaction between the different factors impacting the development/evolution of the STEM teachers' identity. The study is guided by the following research questions:

1) How did Egyptian STEM teachers' identity evolve over the course of the STEM experience in model STEM schools in Egypt?

2) How did the political and structural characteristics of the STEM schools and teachers developing STEM identities interact and co-evolve?

3) What do Egyptian STEM teachers identify as being important characteristics of STEM teachers
\end{abstract}

Methodology: A multiple holistic case study design was used to explore the research questions within the bounded context of an established Egyptian STEM school.

Methods: Data for this study were drawn from (1) semi-structured interviews conducted with seven teachers from an Egyptian STEM school and (2) document analysis of Ministry of Education decrees and the published reports of Education Consortium for the Advancement of STEM in Egypt.

Results: Using inductive and deductive data analysis, teachers were found to have undergone a deep transformative change process from a traditional teacher into teachers with a progressive mindset and student-centered classroom practices. The teachers developed strong conceptualizations of the STEM education, stressed the importance of collaboration, critical thinking, and motivation for teachers seeking to work in a STEM setting, and considered themselves moving towards established STEM teachers' identity.

(Continued on next page)

*Correspondence: elnag003@umn.edu

STEM Education Center, University of Minnesota, Minneapolis, USA

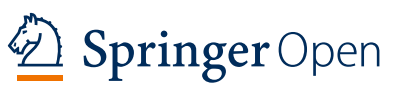

(c) The Author(s). 2020 Open Access This article is licensed under a Creative Commons Attribution 4.0 International License, which permits use, sharing, adaptation, distribution and reproduction in any medium or format, as long as you give appropriate credit to the original author(s) and the source, provide a link to the Creative Commons licence, and indicate if changes were made. The images or other third party material in this article are included in the article's Creative Commons licence, unless indicated otherwise in a credit line to the material. If material is not included in the article's Creative Commons licence and your intended use is not permitted by statutory regulation or exceeds the permitted use, you will need to obtain permission directly from the copyright holder. To view a copy of this licence, visit http://creativecommons.org/licenses/by/4.0/. 


\begin{abstract}
(Continued from previous page)
Conclusion: This study concluded that STEM teachers' identity can be viewed as a dialogical, dynamic, and evolving process that results from the interaction of personal and professional traits within new educational experiences exemplified by the new and different experiences in their STEM schools.

Despite several challenges, such as limited resources and influence from the bureaucracy and norms of the traditional education system, the teachers still persist in their professional growth and desire to impact the larger context of the Egyptian education system.
\end{abstract}

Keywords: STEM education, STEM education in Egypt, Education change, Teacher identity, Case study

\section{Introduction}

The Science, Technology, Engineering, and Mathematics (STEM) movement in Egypt has been considered a "revolution inside a revolution" since it coincided with the January 2011 Egyptian popular uprising (Abouserie \& Merlino, 2014; Rissmann-Joyce \& El Nagdi, 2013). The goal was to change the stagnant status of the Egyptian education system characterized by outdated curricula, traditional methods, emphasis on factual knowledge and theory at the expense of hands-on activities, limited access to appropriate technologies, and insufficient budgets (ElDeghaidy, 2017) to a more student-centered approach where critical thinking, innovation, and hands-on work are emphasized (Ministry of Education (MoE), n.d.). The development of STEM schools was central to reenvisioning education in Egypt (Egypt vision 2030, n.d.), with two model STEM high schools opening in 2011 for boys and 2012 for girls. The schools' mission has been to foster the development of socially responsible leaders who are equipped with capabilities of design, innovation, and critical thinking, as well as the knowledge and skills to address the grand challenges of Egypt (Education Consortium for the Advancement of STEM in Egypt (ECASE), 2013a; Rissmann-Joyce \& El Nagdi, 2013; USAID, 2016; World Learning, n.d.).

Teaching in a STEM school was a new experience for the teachers who started this journey in 2011. They embarked on this new professional journey equipped with the old tools of the traditional system, and the necessary shifts in classroom practices presented a steep learning curve for teachers requiring the development of a new identity as a STEM teacher. Given the limited research on how teachers develop STEM identities (El Nagdi, Leammukda, \& Roehrig, 2018), exploration of the experiences of these Egyptian STEM teachers will provide additional information about the development of a STEM teacher identity. Specifically, this study explores how Egyptian STEM teachers navigated the new system and coped with the associated challenges, both personally and professionally, and explored the ways their identities as STEM teachers have evolved. To this end, the study was guided by the following research questions:
1- How did Egyptian STEM teachers' identity evolve over the course of the STEM experience in model STEM schools in Egypt?

2- How did the political and structural characteristics of the STEM schools and teachers developing STEM identities interact and co-evolve?

3- What do Egyptian STEM teachers identify as being important characteristics of STEM teachers?

\section{Literature review}

With the increasing reliance on STEM as an education reform initiative in different parts of the world (Ritz \& Fan, 2015), there is a need to understand the nature and meaning of this approach in terms of policies, programs, and implementation. A primary goal of these reforms is to enhance STEM literacy which includes "the conceptual understandings and procedural skills and abilities for individuals to address STEM-related personal, social, and global issues [within the framework of] integration of STEM disciplines" (Bybee, 2010, p.31). In response to STEM initiatives, there has been an increase in the number of STEM schools designed to specifically address these goals and provide new educational experiences for students (Herschbach, 2011; Subotnik, Tai, Rickoff, \& Almarode, 2009).

The STEM movement initiated in the USA has led to various attempts to replicate it in different places around the world (Bybee, 2010, 2013; Forman et al., 2015; Ritz \& Fan, 2015; Sanders, 2009). Countries all over the world perceive STEM education as a vehicle for preparing their future generations in a highly competitive global economy (National Science and Technology Council, 2013; Reeve, 2013; Ritz \& Fan, 2015). This globalized perspective has an economic policy agenda that focuses on "enlarging the STEM skilled workforce to engage in research and development, industry innovation and effective responses to technological change; lifting the overall scientific literacy of the population; attracting more students to study STEM at senior secondary and university levels" (Gough, 2014, p. 446). Such efforts, prompted by the global financial crisis and intense competition, hopes that coordination and integration of STEM activities will help equip a workforce for dealing 
with the contemporary nature of business and industry, and encourage more school leavers to seek further training and employment in areas of engineering and science (Dugger, 2010; Honey et al., 2014; Sanders, 2009). Though the motives behind these STEM initiatives appear uniform across nations, implementation may be different given the difference in political, social, and technological history of each country around the world (Ritz \& Fan, 2015; Williams, 2011). Thus, it is important that research considers the unique culture and situation within any particular country.

Creating a STEM reform, like all other reform endeavors, cannot take place overnight. Bybee (2010) provides a model for adopting, sustaining, and evaluating STEM education reform that occurs over the course of a decade (see Table 1).

This study falls within the first two phases in Bybee's (2010) model. STEM education reform starts with introducing the STEM initiative, which takes almost 2 years for instructional units to be designed, developed, and implemented. Within this study, the initial preparatory period encompassed the preparation of a whole new school system from organizational structures, hiring and training teachers and leaders, developing curriculum, admitting students, to providing schools equipment and resources. The second stage takes place for 6 years following the initiation of the STEM reform. Within the context of this study, the successes and failures of the STEM schools were continually reflected on resulting in policy changes and programmatic redesign.

\section{Conceptual framework \\ Fullan's change theory}

Bybee's model requires that teachers change their practices at the school, local, and national levels to bring a STEM reform to scale. This change in teaching practices is a result of a deep transformation process. Similarly, Fullan (2006) argues that for any educational reform initiative to succeed, a change in instructional practices inside the classroom, in addition to a deeper cultural change in the larger context, provides evidence of change. He introduces the term "lateral capacity building" where the individual stakeholders and their respective organizations embrace reform. With knowledge of desired changes and motivation, the larger context can begin to shift. However, in Fullan's (2006) model, some distractors may be barriers to changing context including unnecessary bureaucracy, collective bargaining conflicts, and managerial issues (Fullan, 2006).

Fullan (2006) describes seven principles for ensuring a successful change: motivation, capacity building focused on results, learning in context for those enacting reform, capacity to change the larger context, reflective action, tri-level engagement, and persistence and flexibility. Motivation and engagement are vital for the success of educational reform, and all other premises depend upon motivated and engaged stakeholders. However, moral commitment to reform is not enough to produce change; commitment to reform must be accompanied by attention to identity, capacity, resources, and support. Involving teachers in decision making increases motivation as teachers take ownership of ideas, which in turn increases readiness and interest in using learningconducive practices in the classrooms (Hendricks, 2009). This can be manifested in different ways including establishing communities of practice that work together to develop their practices of teaching through a collaborative process of professional learning (Lave \& Wenger, 1991). Cultural shifts are not easy as they require negotiation of identities, new norms, structures, and processes. Modeling of desired values and behavior aids in the displacement of existing, undesirable norms (Fullan, 2006).

Tri-level engagement, including the school/community, district, and state, is essential to ensure that educational reform efforts are successful and sustained. Fullan (2006) explained that complete alignment of the three is often difficult, but a goal of "permeable connectivity" can be realized when "mutual interaction and influence within and across the three levels" (p.11) takes place.

\section{Teacher identity}

As part of the change process, teachers develop new or evolving identities as a result of the interaction between their personal experience and the new teaching situation or context they are placed in (Akkerman \& Meijer, 2011; Watson, 2006). Research on teacher identity has explored how these identities are formed, the factors that influence changes of identities, and the role these

Table 1 A decade of action: phases and goals

\begin{tabular}{|c|c|c|}
\hline Phase & Timeline & Goal \\
\hline Initiating STEM education reform & 2 years & Design, develop, and implement model instructional units \\
\hline Bringing STEM reform to scale & 6 years & Change policies, programs, and practices at local, state, and national levels \\
\hline Sustaining STEM education reform & 2 years & $\begin{array}{l}\text { Build capacity at the local level for continuous improvement of school } \\
\text { science and technology programs }\end{array}$ \\
\hline Evaluating STEM education reform & $\begin{array}{l}\text { Continuous with a major } \\
\text { evaluation in } 10 \text { years }\end{array}$ & $\begin{array}{l}\text { Provide formative and summative data on the nature and results of the } \\
\text { reform efforts }\end{array}$ \\
\hline
\end{tabular}

Source: permission granted from ITEEA June 4th 2020, Bybee, 2010, p.34 
identities play in students' and teachers' motivation and learning (Alsup, 2006; Franzak, 2002; Schutz, Hong, \& Francis, D. C. (Eds.)., 2018). However, research on STEM teacher identity is limited.

In this study, while looking at teaching as a relational sociocultural practice (Biesta \& Stengel, 2016), teacher identity is conceptualized as a dynamic, continually changing, and active process which develops over time through interaction with different policy, school, and classroom environments and those who work in them (e.g., Franzak, 2002). This is viewed as part of the change process that happens to teachers while undergoing new professional experiences leading to a process of creating new or multiple identities. The interaction between old established identities and new emerging ones results in an "identity fluidity" or "instability" (Beauchamp \& Thomas, 2009; Day, Kington, Stobart, \& Sammons, 2006).

As noted by Fullan (2006), the cultural shifts needed to create meaningful education reform take place over time. Bybee, 2010 provides a timeline for this system level reforms specific to STEM. Fullan's (2006) change theory also identifies identity and ownership as important in motivating teachers to change, linking systemic education reform to the development of new teacher identities necessary to sustain a reform initiative. Teacher identity development takes place through a sustained and reflective reform process (e.g., Day et al., 2006), which over the course of a decade can lead to a major reform in the education system (Bybee (2010); Fullan, 2006). While systemic change cannot happen without parallel shifts in teacher identity and practices, it is also assumed that evolution of teacher identity and practices within an education setting may not occur without a sustained effort towards consolidating that change at the system level, all of which takes place over an extended time frame (Bybee, 2010) (see Fig. 1). In the Egyptian context, failing to create this sustained effort has resulted in forfeiting the positive results of many reform initiatives (Ibrahim, 2010).

\section{Methodology}

\section{Context and purpose of the research}

This study used a multiple holistic case study to explore the experiences of Egyptian STEM teachers working in an Egyptian model STEM school (Yin, 2014). The overarching purpose was to understand teachers' developing roles and identity in the Egyptian STEM setting. Each participant constitutes a unit of analysis in the case study. Case study was chosen because of its utility to provide depth into contextually rich situations (Yin, 2014). The proposed case study is descriptive and analytic in nature as it closely examines and attempts to describe a phenomenon (roles and characteristics of
Egyptian STEM teachers) in a real-world context (STEM schools in Egypt).

\section{STEM experience in Egypt}

Egypt's education system ranks very low in terms of the quality of education, being ranked 133 out of 137 in 2018 in the quality of primary education and 130 in the quality of education system as a whole (The Global Competitiveness Report, 2018). In addition, students' achievement on international exams, such as The Trends in International Mathematics and Science Study (TIMMS), is comparatively low, and Egypt ranks in the under-average segment (Provasnik et al., 2016). Additionally, according to the Egyptian Pre-University Education Strategic Plan (Egypt Ministry of Education (MoE), 2014a, 2014b), students' interest in science and mathematics has been declining, and they concluded that "there was a reluctance of preparatory stage graduates to join the scientific section of the general secondary certificate with only $10 \%$ of them whereas the rest join technical secondary education or the literary section of the general certificate" (p.41).

\section{Policy window}

The STEM reform initiative came into existence as a reaction to the negative state of STEM education in Egypt. And with the advent of the Arab Spring, especially the January 25th, 2011 Revolution, new hopes of genuine and real change flourished. The Arab Spring provided what might be called the "window of opportunity" for such a change. The first two STEM schools, a boys' school in 2011 and a girls' school in 2012, have been unique schools in the country and subsequently 13 more STEM schools have been opened. The first two model STEM schools were, and still are, single-sex boarding schools that use a centralized national, highly competitive selective admission process (Rissmann-Joyce \& El Nagdi, 2013) to secure equal access. The schools' mission is to foster the development of socially responsible leaders who are equipped with capabilities of design, innovation, and critical thinking as well as the knowledge and skills to address the grand challenges of Egypt (Rissmann-Joyce \& El Nagdi, 2013; ECASE, 2013a).

Egyptian teachers have been historically marginalized through top-down decision-making processes regarding policy level issues and curriculum development (Megahed, 2008). However, the STEM reform initiative promised a different paradigm where teachers were invited to play a role in curriculum design and subsequent implementation (ECASE, 2012). At the same time, Egypt embarked on a new reform vision in all domains including education where STEM can be a model (Egypt visions 2030, n.d.). However, the teachers faced numerous challenges with this new system: attitude towards new student-centered 


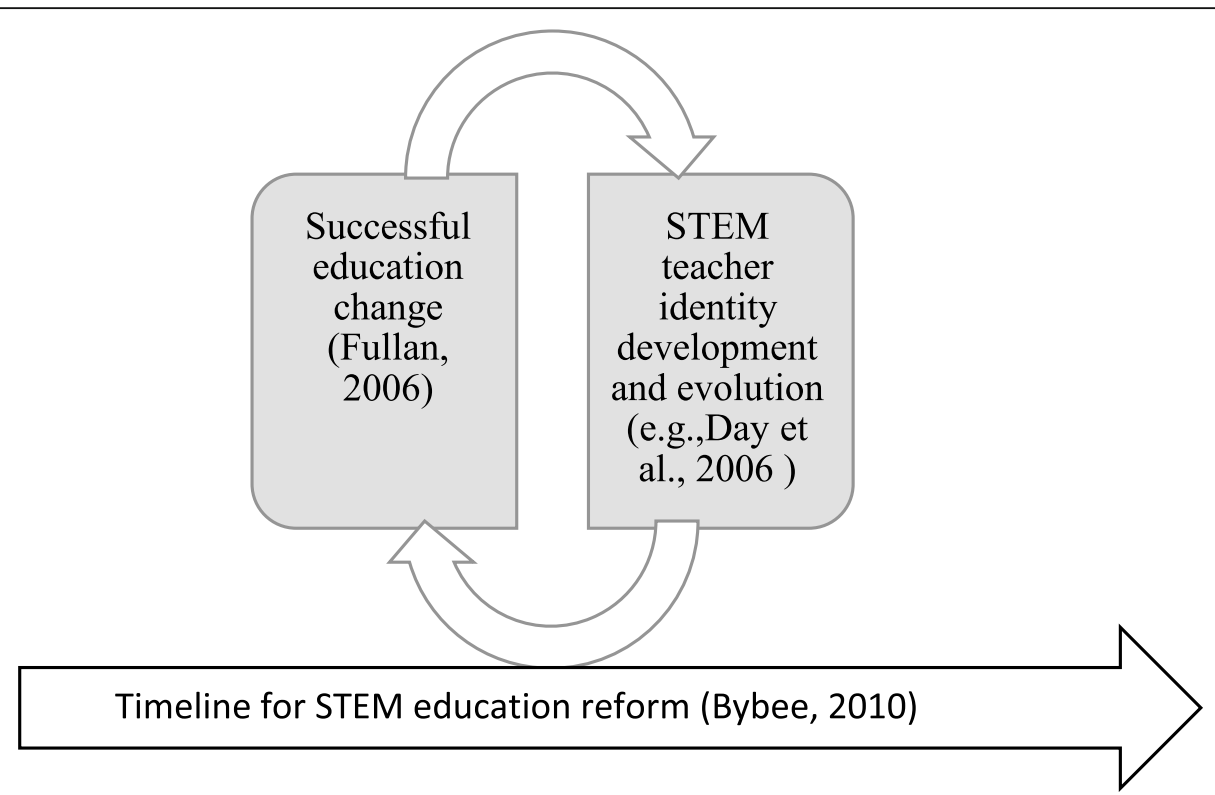

Fig. 1 Conceptualizing the relationship between chronological/sustained view of STEM reform with Fullan's perspective of education change and teacher identity development

pedagogy, being open to students' critiques, using up-todate technologies, using different forms of assessment, and collaborative work (Abouserie \& Merlino, 2014; Rissmann-Joyce \& El Nagdi, 2013).

\section{Participants}

The participants were six STEM teachers from the first two STEM schools and an engineering specialist who was in charge of developing the engineering challenges for all STEM schools (see Table 2). The participants were purposefully selected to be teachers of mathematics, science, engineering, and social studies who have been working in a STEM school for at least 5 years. The two STEM schools were brand new schools; thus, the entire administrative and teaching staff were purposefully hired from other schools. All of the participants had previous teaching experiences in traditional public schools, ranging from 3 to 21 years.

\section{Data collection}

The primary data source of this study was semistructured interviews with the participants. Interviews were conducted in Arabic with the participants for ease of communication. Sample interview questions are included in Table 3. The secondary data source was a document analysis of the MoE ministerial decrees outlining the goals, vision, and evaluation system used in the STEM schools and other teachers' pertinent documents like lesson plans; and the ECASE available published reports on the project. These documents provided sources for what institutions (MoE and ECASE) envisioned as STEM education, STEM integration, and the purposes of the STEM initiative in the Egyptian context. As Hodder (1994) notes, documents have no meaning unless they are situated in context, these policy documents and reports were reviewed in the light of the teachers' experiences in the STEM setting and their

Table 2 Participant demographics

\begin{tabular}{lllll}
\hline Name $^{\text {a }}$ & Age & Subject & Teaching experience & Teaching experience in STEM school \\
\hline Mona & 50 & Biology & 27 & 6 \\
Samir & 43 & Physics & 22 & 5 \\
Amr & 44 & Math & 25 & 5 \\
Ramy & 46 & Chemistry & 25 & 5 \\
Omar & 45 & Technology & 20 & 6 \\
Amir & 46 & Social studies & 25 & 6 \\
Mohamed & 38 & Engineering & 10 & 7 \\
\hline
\end{tabular}

${ }^{\mathrm{a}}$ Teachers names are pseudonyms 
Table 3 Research questions aligned with interview questions

\begin{tabular}{ll}
\hline Research questions & Sample interview questions \\
\hline How did the political and structural characteristics of the & 1- How can you describe your journey in the STEM school: \\
STEM schools and teachers developing STEM identities & academically, professionally, and personally? \\
interact and co-evolve? & 2- In what ways were STEM teachers in Egypt's model STEM \\
& schools involved in designing STEM curricula? \\
& 3- Have you been part of curriculum development in your \\
& subject area and/or the capstone? \\
& 4- Describe your role in the curriculum development, if at all. \\
& 5- What challenges and/or successes did they have while \\
implementing STEM-integrated curriculum? & 6- How can you compare yourself professionally now and \\
the course of the STEM experience in two model STEM & before joining STEM school? \\
schools in Egypt? & - What is your philosophy of teaching? \\
& 8- What is STEM from your point of view? What comes to \\
& your mind when you hear the word STEM? \\
What do Egyptian STEM teachers identify as being & - How did it (philosophy of teaching) align with your \\
important characteristics of STEM teachers? & conceptualization with STEM? \\
& 10 - How do you identify yourself as a STEM teacher? \\
& STEM teacher? \\
\hline
\end{tabular}

conceptualizations of STEM education, integration, and their roles in the STEM schools.

A limitation of our data collection is not having observational data of teachers' instructional practices; permission for observations was not obtained. However, the first author was directly involved in the first stages of the initiation and development of the school being studied and was a teacher and teacher leader at that STEM school for 4 years. This provided an important contextual understanding of the factors, incidents, and learning experiences described by participants that constituted identity development.

\section{Data analysis}

First, MoE and ECASE documents were reviewed to identify their conceptualizations regarding STEM education, STEM integration, the roles and characteristics of teachers in curriculum development, and regulations for teachers' recruitment. Though these documents were mainly utilized to provide background and context for the study, they were integrated in the qualitative data analysis of the teachers' interviews.

Second, interviews were transcribed and translated from Arabic into English by the first author. They were then analyzed using open inductive and axial coding strategies (Corbin \& Strauss, 2015). An iterative process of inductive coding from the data allowed for deep and comprehensive thematic analysis. Several codes emerged from the initial analysis including, but not restricted to, cooperation, belonging, curriculum involvement, professional development, students' successes, and the need for sustainability. Inductive open coding allowed themes to emerge organically from the participants and provided deeper understanding of specific contextual elements (Miles, Huberman, \& Saldana, 2013), which lent themselves to a deductive iteration where the codes from the interviews were compared with the themes from the document analysis (Hodder, 1994) as well as elements found in previous literature. Axial coding was used to further disaggregate codes into salient and organized themes through constant comparative methods (Corbin \& Strauss, 2015; Miles et al., 2013).

The authors worked closely for a period of more than 4 months in an iterative dialogic manner to refine interpretations of certain data pieces and how they fit the overall thematic analysis as well as relevant literature and conceptual framework. For instance, as a result of iterative data analysis going through the vertical (per participant) and horizontal (across participants) coding, one of the major changes was the shift of emphasis from looking at the professional journey of the teachers as a global topic to a closer look at the identity evolution with all its interacting aspects within this specified context.

\section{Findings \\ STEM policy context}

As part of the initiation process of the STEM reform movement, the Egyptian Ministry of Education (MoE) released a set of guiding principles to guide the development of STEM schools (ECASE, 2013b) (see Table 4). The MoE also issued several decrees (MoE decrees 369/ 2011, 202/2012，382/2012，308/2013，172/2014, 313/ 2015) to organize students' admission, evaluation systems, school boards, hiring teachers and staff, curricula, the establishment of a centralized body in the MoE identified as the "STEM Unit" to oversee and expand STEM education in Egypt, and finally to establish regional bodies in the Governorates. 
Table 4 STEM schools design principles

\begin{tabular}{ll}
\hline Principle & Description \\
\hline Principle 1 & $\begin{array}{l}\text { Value and consolidate progressive education practices, including project-based learning, to prepare } \\
\text { students to demonstrate their ability to think independently, creatively, and analytically }\end{array}$ \\
Principle 2 & $\begin{array}{l}\text { Prepare students to be scientifically, mathematically, and technologically literate and proficient, able } \\
\text { to apply their understanding to advance creativity, innovation, and invention with a real-world vision }\end{array}$ \\
Principle 3 & Promote an environment of questioning, collaboration, and high level of communication \\
Principle 4 & Value and promote self-motivation, self-direction, and lifelong learning \\
Principle 5 & Engage partnership to accelerate school capacity and broaden student, teacher, and administrative \\
Principle 6 & opportunity \\
Principle 7 & Ensure all graduating students will be admitted to and be competitive in a university and then in \\
& the Egyptian labor market as well as the world labor market \\
& Foster the development of socially responsible leaders with consciousness and eye toward a more \\
& contemporary Egypt-solving the future while addressing the largest grand challenges
\end{tabular}

Curriculum for the STEM schools in Egypt, originally developed by the ECASE, was school-driven curriculum, i.e., its development was built on the feedback from teachers and students in the schools. The process was initiated in a Design Studio workshop including teachers, principals, and MoE officials and focused on the Egypt's Grand Challenges as the context for curriculum (ECASE, 2012, pp.12-13).

In addition to the content area curricula, an integrated STEM capstone course was designed to help create a context for integration where students could apply their learning from their content courses to address one of Egypt's grand challenges (Rissmann-Joyce \& El Nagdi, 2013; ECASE, 2012; , 2014; , 2016). According to ECASE (2012) "these capstone projects provide the cornerstone of inquiry-driven, project-based STEM education and also are an important aspect of the STEM curriculum and standards framework" (p.12). The purpose of capstone projects was to bring rigorous, real-world STEM challenges into the classroom for all students to engage with inquiry learning in a manner aligned with the MoE Guiding Design Principles (Table 4). The first implemented capstones were developed by external curriculum developers. The expert team developed a manual for teachers to use while implementing the capstones (ECASE, 2012; , 2013a). A gradual handing over of responsibilities for the capstone work to Egyptian teachers occurred (ECASE, 2014; , 2016) and teachers in the schools assumed their roles as capstone facilitators, leaders, and designers. Table 5 shares capstone design challenges by grade level.

\section{A parallel development journey}

Table 6 provides a timeline of the development of the STEM project based on the document analysis and the work and/or input of the participant teachers aligned with Bybee's model.

\section{Aspects of teachers identity evolution}

From the vertical and horizontal data analysis of the different data sources, mainly teachers' interviews (Miles et al., 2013), a set of five themes emerged that reflected the professional journey of the Egyptian teachers in this STEM school with all its successes and challenges displaying a vivid picture of the evolution of their identity as STEM teachers, and what they saw as important characteristics of STEM teachers. The five themes are categorized to represent a cluster of aspects that help identity evolution for STEM in established STEM schools (see Fig. 2).

Five themes emerged that characterized the teachers' identity evolution through the phases of initiation of the STEM reform and brought the STEM reform to scale: including teachers' changing beliefs, developing conceptions

Table 5 Capstones per year per semester aligned with grand challenges ${ }^{\mathrm{a}}$

\begin{tabular}{lcc}
\hline Grade10 & Grade 11 & Grade 12 \\
\hline Semester 1 & Semester 1 & One capstone per year \\
$\begin{array}{l}\text { Improve use of arid areas, } \\
\text { urban congestion }\end{array}$ & Clean water, reduction of pollution; recycling; increase & Students choose one of the following: \\
industrial base for Egypt & 1-Medical and public health improvement \\
Semester 2 & Semester 2 & 3-Reduction of pollution \\
Improve the use of & Improve the scientific and technological environment for economic and \\
alternative energies & for to increase the industrial and agricultural bases of Egypt & 4-Increase and develop agricultural and \\
& & industrial base for Egypt \\
\hline
\end{tabular}

\footnotetext{
aThese capstone challenges are open for change according to curriculum changes that may occur over the course of implementation and ongoing evaluation
} 


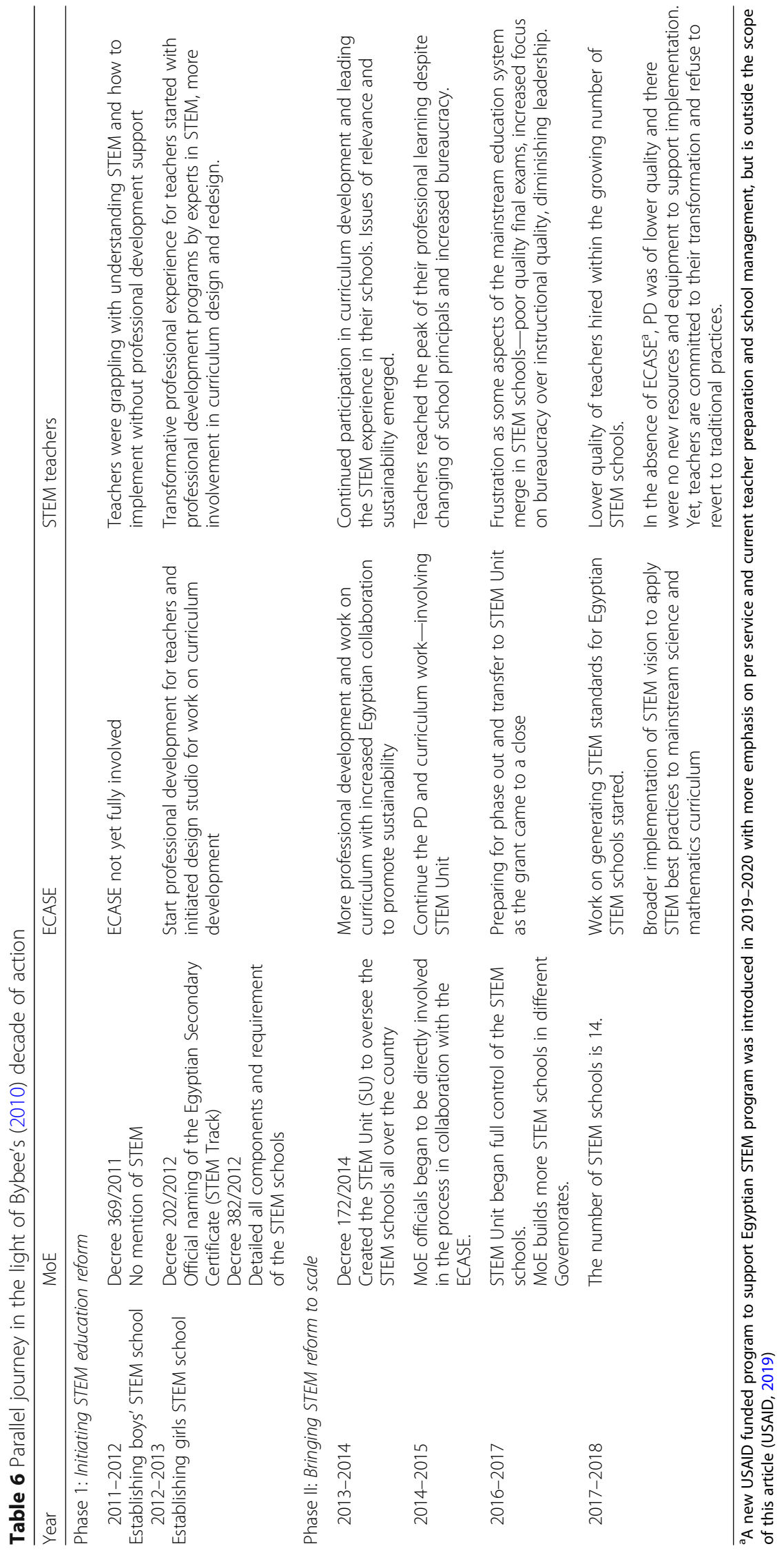




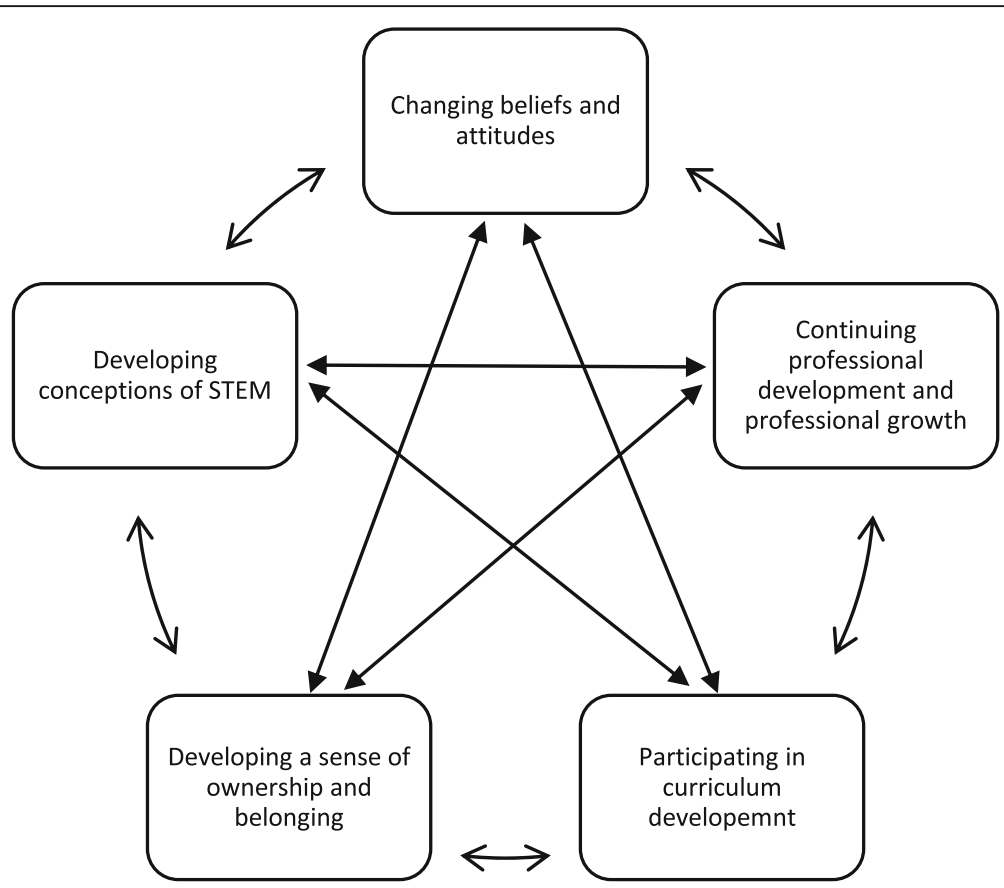

Fig. 2 The dialogical relationship between the different aspects of the evolution of STEM teachers' identity

of STEM, continuing professional development, professional growth, taking part in curriculum development, and creating a sense of belonging and ownership to the STEM school as an institution. In this section, these themes are elucidated to show how they cluster around identity evolution, first as individual themes and second through exploring the relationships and interactions between the themes.

Identity evolution in this case is seen as a manifestation of the tension between established and evolving identity. Developing a STEM teacher identity in a new STEM school with lofty and challenging requirements was a complicated process for the teachers. Though they viewed themselves, at the time of data collection, as accomplished STEM teachers, they still had tension between their identities as both being a disciplinary teacher and a STEM teacher.

Ramy, a chemistry teacher, stated that he was a " $55 \%$ STEM teacher". He calculated this percentage by the amount of time he spent in teaching using STEM practices and pedagogies as opposed to "content knowledge transfer using 'traditional' methods to ensure students are able to answer final examinations". Similarly, Mona thought that she was

60\% STEM teacher. STEM teacher and biology teacher are two faces of the same coin. In an 80minute session, I spend around 60\% doing STEM work; teaching strategies, checking understanding, using the backward design, using different assessment modes like KWL, etc.
Likewise, Samir, a physics teacher, thought he was "80\% accomplished STEM teacher though I started the journey from scratch. I would consider myself as a STEM teacher with physics between brackets [STEM (physics) teacher]". At the other end of the continuum, Amir, a social studies teacher, identified himself as

a $100 \%$ STEM teacher. I do what a STEM teacher should do in classroom. I apply all the STEM teaching strategies, make the connections, and by time I started independently working on myself regarding professional development and helping other teachers and students. I developed from a social studies teacher, to a capstone teacher, and leader and I enjoy helping students in their projects even when I am not their capstone leader.

Omar, the computer science teacher, thought that he could identify himself as a STEM teacher as,

it was more comprehensive. I think I am $75 \%$ STEM teacher. Being a STEM teacher is larger in scope than a computer science; I do more than just teaching computer science. I help the girls to solve problems in their projects by guiding them to the best places to get the right answers to their questions or the technical help for their projects. For instance, I helped the girls in different projects to design certain solutions using programming language. 
As pointed out by all interviewed teachers, collaboration is axial to success in a STEM setting and as such identity evolution was both individual and connected among the teachers. Samir stated that

you cannot continue in a STEM school if you can't collaborate with others or trying to show that you have all the truth and you are the best. You will be like a plastic gear in a machine of metal gears; you will be crushed out and repulsed unless you show flexibility and openness for learning.

Amr, a mathematics teacher, considered collaboration with teachers of other subjects necessary "for instance in physics and math. Our collaboration is crucial to make learning better for students as there are a lot of things in common". Amir thought that one of the basic qualities of an effective STEM teacher was to think of himself or herself as "part of a whole with readiness to work together and learn from each other".

Towards this process of identity evolution, different aspects interacted and these aspects constituted an overlapping portrait of how a STEM teacher identity can evolve (Fig. 2). Each of the five aspects is detailed in the following sections.

\section{Developing a sense of ownership and belonging}

As a result of the efforts exerted by the teachers, the students started to achieve success in various STEM fairs and competitions. This caused increased public interest and media coverage, and teachers had a time of satisfaction and developed a sense of ownership that their efforts were not in vain, especially from year 2 through year 5. Omar remembered the first few years of the experience where teachers "stayed in the school for long hours to help students in their work in the projects or in their subjects". Amr, the mathematics teacher, explained that he "had to spend long time with students after school to help them in mathematics and cover the gaps in their mathematical knowledge between what they already know and what the new curriculum required". Amir argued that despite the challenges that they "faced due to work pressure, higher demands from students, and bureaucratic problems, it is very hard to leave the STEM school and go back to my old school". Mona considered the STEM school as

home and students as children whose success gave a sense of satisfaction that she had fulfilled her job. Students who graduated from school- and are in colleges- are still in contact. I developed a family bond with them. I feel proud when they tell me that they mentioned their STEM experience with pride to their professors.
In the face of the different challenges at the STEM schools, teachers maintain hope, as Mohamed stated, "there is still hope and the momentum we had in the first years of the experience is still pushing us forward". They had no intention to go back to the old teaching approaches, as Amir put it, "I can't go back to my old school or methods of teaching."

\section{Professional development and professional growth}

Transitioning to a STEM school was not an easy task for teachers, all of whom were experienced teachers with 10 to 26 years of teaching in traditional school settings. They described the journey as sometimes thorny but ultimately transformative. Ramy considered his STEM experience as a "rebirth after being frustrated and burnt out after a 20-year experience as chemistry teacher in traditional secondary schools. I started to widen and deepen my concepts, and I started to find purpose and result of what I teach". Omar found "light at the end of the dark tunnel after serving as a computer science teacher for more than 20 years". He added, "Here [in STEM school], I open the doors and facilitate learning which was impossible to do at traditional settings." $\mathrm{He}$ went on to say, "though the first year was hard, it was full of learning. Every day you learn a new thing either from ECASE experts, your peers, or even students". Samir described the amount of professional development and learning he experienced in his first year in the STEM school as far as exceeding his 17-year experience in a traditional school. He started his journal as "Physics teacher" but now after almost 5 years in STEM school, he climbed the professional ladder of STEM leadership to "head of department, capstone teacher, leader, and finally, capstone trainer of teachers [ToT] with a different mindset [towards teaching]". Mona described her "professional growth journey" where "through the different PD experiences, collaboration with teachers, interaction with students in their projects, [she] grew as a different teacher and a person".

Mohamed described it as a "journey from skepticism [to belief] in the abilities of students to tackle the challenging tasks and the teachers to implement such a curriculum to belief". He added that a few years later, "when we looked back at the initial tasks [in the capstone] that we used to look at as challenging we started to think that they need to be modified to add some more rigor to them".

\section{Participating in curriculum development}

Curriculum in the Egyptian STEM schools was schooldriven and based on Egypt's grand challenges and national science and mathematics standards (ECASE, 2014, MoE decree 382/2012). The MoE further stipulated, in a revolutionary article in MoE decree 382/2012, that "faculty are 
entitled to decide the topics of each subject area that can achieve the learning outcomes of their curriculum all over the academic year". ECASE and MoE involved teachers in curriculum development in a variety of ways. Initially, design studios where all stakeholders were involved, including teachers and STEM experts, brainstormed the grand challenges to develop connections between subjects. ECASE described the iterative process as "leverage[ing] Egyptian STEM teachers to provide local contextualization to the content and to essentially create course material fully customized to Egypt". Given the complex nature of the contextualization process, "mapping, alignment, publishing, and beta testing of the content occur[ed] in waves over the [first] year" (ECASE, 2012).

Mona, as one of the early STEM teachers, reflected on her experience with curriculum design:

I used to design my curriculum in the first year. Then with ECASE we had first draft in the design studio and then apply it and reflect on the application in the [following] design studio in the summer to redesign and so on for three years.

In addition to that, Mona explained that her "colleagues participated in developing STEM standards for Egyptian STEM schools which are not in use to the moment". Omar referred to the process of creating the Egyptian STEM standards that happened in 2016 [fifth year of the project] and the last year of the ECASE tenure:

new committees were organized to develop STEM standards [for each subject]. These committees included a faculty member from the university, a teacher, and a member form the MoE curriculum center. These standards were developed and sent to each subject consultant at the MoE and they are still there.

Mohamed played a role in designing the capstone challenges with other Egyptian teachers and experts, with the full support of the ECASE. He "participated in capstone design challenges and after the ECASE left, [he] was in charge of developing them [design challenges] and making them deeper and more challenging". Amir participated in developing the social studies curriculum, "I developed the social studies learning outcomes with a colleague in the other STEM school." Ramy had the challenge of trying to settle the identity of the curriculum they should be using in the schools. He participated once in curriculum development where he was trying to figure out what kind of curriculum they are teaching in STEM schools: "is it [International English Certificate] IG, IB, or Egyptian Secondary
Certificate (Thanaweya Amma), I was told that we are studying/ teaching STEM." Meanwhile Amr objected to the thematic approach of having a grand challenge or theme and then building the curriculum around it.

\section{Teachers' changing beliefs and attitudes about success in STEM}

To be a successful STEM teacher in such a challenging context, there should be some indications of readiness or aptitude for the job. All interviewed teachers argue that the major indications include believing in the role students have in the learning process, and the ability to transition from being a disciplinary teacher to a collaborative STEM teacher. Before coming to STEM school, Samir personally believed in motivating students to learn but "it was hard to do it well in the traditional school." Whereas in the STEM school, this was the norm. Samir argued, "Learning can happen better if motivation is created in the students' minds and hearts. The teacher's role is to create that motivation and get students ready for an effective learning process." In his view, STEM provided that opportunity for "students to embark on different learning opportunities that put them in the seat of the leaders and problem solvers of their country's grand challenges". Mohamed concurred that even before joining STEM schools, he personally believed that "motivation drives learning. Therefore, students who join these schools need to be highly motivated, pushed, and challenged to get the highest possible results. And this is what STEM requires." Amir believed that he had "a STEM teacher inside him" even before coming to STEM school. He used to

try some of the active learning pedagogies like role play, asking students to do some research and prepare work for class, class discussions, but at a minimal level in my previous school. These were very effective strategies but not welcomed in that setting in contrast with the STEM setting where most of our work is based on such strategies.

\section{Developing conceptions of STEM}

The first MoE decree to establish he schools never mentioned the term "STEM" or its equivalent in Arabic, and nothing was specified in the document about the intended curriculum. Subsequently as Mona stated, "teachers and students had a hard time trying to figure out what to teach and how to teach in a STEM school before the ECASE took over." The teachers knew STEM to be connected to project-based learning, so as Mohamed said, "we tried to brainstorm project ideas for students to work on." According to Amir, in the girls' school, "the capstone was postponed to the second semester [as we were] not ready in terms of curriculum 
and resources." Overtime, teachers developed two general conceptualizations of STEM: one as a policy level reform initiative and the second as a pedagogical tool to facilitate more student-centered teaching and learning.

Policy reform level One year or so after the initiation of the STEM experience, policy making institutions promoted a conceptualization of STEM as an educational reform initiative in which curriculum was based on integrated STEM units that utilized project-based learning and inquiry in a transdisciplinary manner that better prepare students to labor market (ECASE, 2012; MoE decree, 382/2012). Similarly, STEM was viewed by the teachers as an attempt to link learning to life and prepare students for the labor market. Samir argued that

STEM is an education system that makes students ready for life. Students link what the concepts they learn to everyday life issues and work towards solving problems. They do this through integrated curriculum, project- based learning through the design process, group work, having better communication skills and other skills like critical thinking essential for competitive labor market.

Amir argued that "STEM is a reform system that introduces certain strategies like project based learning and inquiry into the classroom in order to stimulate students to work more independently and critically to solve their country's grand challenges." For Mona, STEM was conceptualized as

always to study for life; link learning to life. It is an application of what students learn in schools to their lives. Students were always asking 'why do we learn these things?' STEM came with an answer which is to be used in their lives. Students are encouraged to contextualize what they learn at school to the Egyptian environment and how they can use this to solve their society's problems.

STEM as a pedagogical tool Ramy considered STEM teaching approaches as a great tool to facilitate learning, "you hook the students and create desire for learning. You provoke students' interest through hands on work, discussions, collaboration etc." Omar thought that "it is all about integration of different subjects in a meaningful context." Through these different tasks, according to Omar, "students got engaged in activities that support their learning and project design and implementation". From an engineering perspective, Mohamed looked at STEM as a gateway to provide 21st century skills. For him, the rigorous, challenging curriculum was one tenet of successful STEM experience:
My conception of STEM is starting with a big theme, develop challenges that are related to real life situations for students to solve, and while trying to solve them, they will need to learn certain concepts in their disciplines and subsequently they will have to learn them. Therefore, students will learn the required content indirectly while learning much more valuable skills of independence, leadership, communication, and develop personal traits of perseverance, and patience.

What I see is that these students come to you with mis-or no conceptions. Therefore, in the first year, you need to work on correcting the misconceptions and to widen their conceptual knowledge because they come from the basic education system that is solely based on memorization. Then you can start introducing projects and other STEM practices.

However, it was evident that Ramy was not heard because curriculum continue to be built around themes and grand challenges, and students start capstone and project work from day one.

In addition to developing curriculum and teaching in their content area, STEM teachers also facilitated students' work in the capstone. In Samir's words, the teacher became one source or reference for the student among numerous other references. He elaborated that a teacher's role is to use his

experience and knowledge to analyze the students' work and direct for improved performance. Your role as a teacher is expanded to more like a moderator of learning or facilitator (in the sense that you are not doing everything or letting the student do everything, there is a certain level of balance where you know when you can interfere to help facilitate the learning process).

Ramy expounded on how his work in the chemistry laboratory differed in the STEM context,

I can do the experiment in different styles that differ according to the audience I am targeting. A girl [student] with good prior knowledge is different from a girl without prior knowledge, different from a girl with prior knowledge and skills. I now have the teaching flexibility to deal with the different types of students.

Being able to integrate or connect their content area with other disciplines or in the capstone was considered a very important asset for a STEM teacher. In Mona's view, 
the teacher should be able to integrate and know a lot about other subjects and how they are connected. How can the learning outcomes in the different disciplines be applied to the capstone? Sometimes, the students can figure this out for themselves by asking them to pinpoint which learning outcomes helped them in their project and in other cases the teacher should help students figure out these connections.

\section{Dialogic interactions between factors that lead to identity development}

The dialogical nature of the factors contributing to the identity evolution, and the new emerging identity portrays an interactive process of professional growth. In other words, when teachers started to have developed a sense of moving towards being identified as STEM teachers, their sense of belonging and ownership increases, their desire to participate in curriculum development is enhanced, and their attitudes towards more progressive education approaches get more positive.

Additionally, teachers' conceptions of STEM developed through their learning in PD and using that learning to develop curriculum. Through reflection on the curriculum, the teachers were able to refine their definition of STEM and improve curriculum in an iterative cycle of improvement. On another level, over time as teachers saw students' success with curriculum, they developed their beliefs became more solidified. The strength of these beliefs develop among teachers within the school not just as individuals creating a collective sense of belonging. This dialogical interaction is seen as one of the principles for constructive knowledge building and professional growth within the STEM community of practice (Ligorio, 2010).

\section{Discussion}

The findings will be discussed in the light of the literature and conceptual frameworks that grounded this study. The findings reveal a vivid picture of a sustained change in Bybee's (2010) terms, a journey towards identity evolution (e.g, El Nagdi et al., 2018; Schutz et al., 2018; Watson, 2006), and an attempt towards an extended reform process (Fullan, 2006; World Bank, 2018).

\section{Bybee's (2010) decade of action}

The STEM school has been in existence now for more than 6 years, a time period aligned with the first two stages in Bybee's (2010) conception of the time span and work requirements to initiate and bring a STEM reform to scale. The details of what has happened during each stage revealed the similarities and differences between Bybee's (2010) understandings and the Egyptian experience, especially in terms of the challenges and successes teachers had during each stage (see Table 6). Throughout phases 1 and 2 of Bybee's model, the participants were engaged in an identity evolution process, cycling between their disciplinary identity and developing STEM teacher identity.

\section{Change theory and Egyptian teachers STEM experience}

The STEM teachers who participated in this study experienced a transformative change journey in their professional life that was initiated by the STEM reform project in Egypt. The journey started with great aspirations and lofty vision to establish a new framework for an education environment that is conducive to learning, creativity, and innovation, which later would lead a wider transformation of the whole education system of the country (World Learning, n.d.; MoE, n.d.). This effort created a motivating context for change, not only in the culture of teaching and classroom practices of the participating teachers, but in their beliefs about effective teaching. This process reflects the major aspect in Fullan's (2006) change theory in which he argued that change in education that does not result in a change in the culture of teaching and classroom practices is futile. One of the biggest sources for motivation, at the time of the STEM initiation, was the wider calls for change in all aspects of the social, economic, and political life in Egypt concurring with 2011 Arab Spring era which provided a window of opportunity for education reform (Kingdon, 1995). This volatile state at the political and social levels became one of the sources of motivation for change in the country.

Within the education system framework, teachers were frustrated with the traditional approaches and welcomed a different mindset for work in their field; Ramy referred to this as a "rebirth" for him as a teacher. This motivation was enhanced by involving the teachers in the curriculum design work and giving them more freedom regarding what they taught in their classes as long as they achieved the learning outcomes. The result was a sense of ownership that had a positive impact on being keen to develop professionally to keep their school up to the expectations. Involving teachers in decision-making concerning curriculum and instruction had a positive effect on not only on consolidating teachers' motivation for change (Fullan, 2006; Hendricks, 2009), but also working towards building a community of practice within the STEM schools (Lave \& Wenger, 1991) by collaborating in teacher training facilitating students' work in their projects and problem-solving at the school level. As a result, classroom practices reflected a change in the beliefs of teachers that students are at the center of the teaching and learning process; teachers systematically changed their traditional approaches towards more student-centered and active learning pedagogies. 
However, one of the biggest issues has been the coordination at the tri-level in Fullan's (2006) conceptualization of change-in this case, the school teachers, the MoE, and the community at large. The MoE set a lofty vision for these schools, yet after the handover of the schools to the MoE STEM Unit, the curve of teachers' motivation started to go down due to a decline in the quality of professional development, increased bureaucracy with little attention to the quality of teaching and learning, mishandling of final assessments for students which shook the public's trust in the STEM system at some point, and less stringent hiring practices to fill the vacancies in the increasing number of STEM schools. In spite of this, the transformation that occurred for teachers was so deep that they were committed to keep going and that "there is still hope and the momentum we had in the first years of the experience is still pushing us forward". They had no intention to go back to the old teaching approaches; as Amir said, "I can't go back to my old school or methods of teaching" reflecting another aspect of Fullan's (2006) theory which is the persistence and resilience.

Rather than focusing on individual teachers, the professional development focused on developing collaboration and improving the education process as a whole (Hargreaves \& Fullan, 2012). In this sense, teachers cannot survive in these STEM schools unless they are collaborative and open to change and learning as Samir warned, "if a teacher thinks he/she knows everything, he/she will not be able to continue in STEM school. We learn a lot of things every day from working together." This clearly corresponds to one of the tenets of Fullan's (2006) theory which is working on changing the larger context as a sign of cultural change. However, sustaining the STEM change (Bybee, 2010) has not been smooth due to different challenges including the "huge resistance to change" on the part of MoE officials and some teachers described by the Egyptian Minister of Education, Tarek Shawky (Shawky, 2018).

\section{Teachers' identity}

Six out of the seven interviewed teachers identified themselves as STEM teachers. This identity evolution took a long time and effort. However, the teachers still cling to their original identities as teachers of stand-alone subject matters reflecting multiple identities (Akkerman \& Meijer, 2011; Cooper \& Olson, 1996). The evolving nature of the teachers' STEM identities reflects the "unstable" and changing identity that is a result of the interaction between different personal and professional experiences (Schutz et al., 2018; Watson, 2006) in an exceptional education setting. These experiences include developing and implementing a very different curriculum that required an interdisciplinary approach, significant collaboration, flexibility, and open mindedness. The teachers experienced several successes at the early stages that motivated their continued learning, such as the $100 \%$ graduation rate of students winning international prizes in science and engineering fairs. Alternatively, teachers also had to overcome barriers to success such as working with a different system of assessments. These experiences garnered a change in attitudes and beliefs and created an irreversible sense of ownership. The intertwined motivation for change and the sense of ownership resulting from the identity formation process provides a strong evidence of how the professional journey of STEM teachers in this Egyptian STEM school has been so transformative. Changes have been accompanied not only by identity evolution, but also capacity building, resources for growth, and mutual support (Fullan, 2006).

One of the biggest findings of the identity development was the tension between teachers' established identities as content areas teacher and their evolving STEM identity. The interviewed teachers set percentages of how much time they perform as a subject matter teacher and a STEM teacher denoting "multiplicity" of identity (Zembylas \& Chubbuck, 2015). While this is an established theme in the literature on teacher identity, in the case of the teachers in this study, it is a reflection of the context where the experience took place and the requirements of the STEM reform. In other words, teachers tend to go back to disciplinary teaching modes in order to cater for the context-specific challenges like parents' concern over their children's score in the final exams, which pushed parents to search for private tuition to help their children (STEM students) in the examinations. Therefore, teachers, in order to convince parents and students that they were qualified teachers with strong content knowledge, resorted to content delivery in the traditional ways causing the tension in identity.

\section{Conclusion}

The journey of the STEM teachers in an Egyptian STEM school was explored within this study through a conceptual framework of change comprised of Fullan's (2006) change theory, teacher identity (e.g., Akkerman \& Meijer, 2011; Watson, 2006), and Bybee's (2010) decade of action to establish a STEM reform endeavor. All in all, this journey revealed a transformative experience in teachers' professional growth and identity development and a deeper change in beliefs and attitudes towards the education process and classroom practices in a studentcentered context. Though in this reform experience, that falls within the first two stages of Bybee's (2010) model of STEM reform, challenges were identified that might cripple the sustaining phase of the STEM initiative (Bybee, 2010). This is particularly the case when considering Fullan's tri-level and the different forms of resistance to change within the Egyptian bureaucratic institutions (Ibrahim, 2010). 
Within the parameters of Fullan's (2006) theory of change, motivation was created through a set of measures like providing an agentic environment for the teachers by involving them in the curriculum development process, taking their feedback seriously concerning the curriculum in the process of redesign, providing continuing professional development programs engaging experts in the field of STEM education in the process, and finally giving teachers leadership roles either in the STEM schools or responsibility for the professional development of other teachers. This motivation was reinforced through the resilience that teachers showed in facing the many challenges in their journey at the school level and the policy level alike. These changes were reflected in teachers' developing culture towards education and classroom practices. This change in classroom practices was evident in using student-centered pedagogies, project-based learning, and the sense of care for students' learning. Although expanding this change to the larger context of the Egyptian education system was one of the tasks of the ECASE and the MoE, the teachers grabbed the opportunity to provide leadership and to help teachers in their schools and teachers in the new STEM schools to join them in this transformative process by providing professional development for their new colleagues. However, sustaining this change (Bybee, 2010), despite these transformative efforts, is in jeopardy due to the resistance to change at the bureaucratic levels in the Egyptian education system (Ibrahim, 2010; Shawky, 2018).

\section{Implications}

Seen within the global urgency to improve K-12 STEM education (El Nagdi et al., 2018), the STEM reform experience in the Egyptian setting has deep implications not only in the Middle East and North Africa (MENA) region but also across the global south. The reform process has been initiated locally, but supported internationally through the USAID. Within this endeavor, Egyptian STEM teachers' contribution is central to the sustainability of the STEM experience. This study is the first of its nature in the Egyptian context that explored teachers' developing roles and identities in a new STEM school system. The findings of the study denote different implications at the professional and policy levels. STEM schools provide an opportunity for professional growth for teachers and quality learning for students when teachers' professional growth is supported through a variety of aspects including, but not restricted to, continuing professional development, creating a sense of ownership and belonging, and involving teachers in curriculum development. However, the challenges at the bureaucratic levels can kill the experience before it can enter the sustaining phase (Bybee, 2010) unless those in charge of the STEM education at the MoE work closely with teachers and listen to their concerns around curriculum, leadership, and assessment issues.

\section{Abbreviations}

ECASE: Education Consortium for the Advancement of STEM in Egypt; MoE: Ministry of Education; STEM: Science, Technology, Engineering, and Mathematics; SU: STEM Unit in Egyptian Ministry of Education

\section{Acknowledgements \\ Not applicable.}

\section{Authors' contributions}

The study was initiated and conceived by MEN. He also collected and analyzed the data and did the theoretical framing and discussion. GR did different rounds of review and editing. The authors read and approved the final manuscript.

\section{Funding}

This research was partially funded by a Haugo Fellowship award and Global Graduate Grant (G3), University of Minnesota, Twin Cities.

\section{Availability of data and materials}

The data and materials used and analyzed for the paper are available with the first author.

\section{Competing interests}

Authors declare that they have no competing interests.

Received: 19 February 2020 Accepted: 24 June 2020

Published online: 07 August 2020

\section{References}

Abouserie, R., \& Merlino, F. J. (2014). A revolution inside a revolution: tales of radical educational transformation in a New Egypt, part 1. Paper presented at the annual meeting of the American Education Research Association. Philadelphia: PA Retrieved from http://www.aera.net/Publications/Online-Paper-Repository/ AERA-Online-Paper-Repository.

Akkerman, S., \& Meijer, P. (2011). A dialogical approach to conceptualizing teacher identity. Teaching and Teacher Education, 27(2), 308-319.

Alsup, J. (2006). Teacher identity discourses. Negotiating personal and professional spaces. New Jersey: Lawrence Erlbaum Associates, Inc..

Beauchamp, C., \& Thomas, L. (2009). Understanding teacher identity: an overview of issues in the literature and implications for teacher education. Cambridge Journal of Education, 39(2), 175-189.

Biesta, G., \& Stengel, B. (2016). Thinking philosophically about teaching. In D. Gittomer \& C. Bell (Eds.), AREA Handbook of research on teaching (5th ed.) Washington, DC: AERA.

Bybee, R. W. (2010). Advancing STEM education: a 2020 vision. Technology \& Engineering Teacher, 70(1), 30-35 Retrieved from https://search.proquest. com/openview/75bbe8b13bf3f54ebd755333ffd8621e/1?pq-origsite= gscholar\&cbl=34845.

Bybee, R. W. (2013). The case for STEM education: challenges and opportunities. National Science Teachers Association.

Cooper, K., \& Olson, M. (1996). The multiple "I's" of teacher identity. In M. Kompf, M., Boak, T., Bond, R., \& Dworet, D. (Eds.). Changing research and practice: teachers' professionalism, identities, and knowledge. Psychology Press.

Corbin, J., \& Strauss, A. (2015). Basics of qualitative research (4th ed.). Thousand Oaks: Sage ISBN \#: 978-1-4129-0644-9.

Day, C., Kington, A., Stobart, G., \& Sammons, P. (2006). The personal and professional selves of teachers: stable and unstable identities. British Educational Research Journal, 32(4), 601-616.

Dugger, W. E. (2010). Evolution of STEM in the United States. 6Th Biennial International Conference on Technology Education Research, (March), 1-8. Retrieved from file:///C:/Users/melna/Downloads/Evolution_of_STEM_in_the_ United_States.pdf

Education Consortium for The Advancement of STEM in Egypt (ECASE). (2012). Progress quarterly report, 1st quarter, year 1 August 28-December 31, 2012. Egypt: Cairo Retrieved from https://www.fi.edu/education-consortiumadvancement-stem-egypt-ecase. 
Education Consortium for The Advancement of STEM in Egypt (ECASE). (2013a) Progress quarterly report, 3rd report. April-June 2013. Cairo, Egypt. Retrieved from https://pdf.usaid.gov/pdf_docs/PA00JQ8D.pdf

Education Consortium for The Advancement of STEM in Egypt (ECASE). (2013b). The STEM Secondary School of Egypt. Student and parent handbook. USAID, Cairo, Egypt.

Education Consortium for The Advancement of STEM in Egypt (ECASE). (2014). Progress quarterly report, 6th quarter, Jan-March, 2014. Egypt: Cairo Retrieved from https://pdf.usaid.gov/pdf_docs/PA00K6M6.pdf.

Education Consortium for The Advancement of STEM in Egypt (ECASE). (2016). Progress quarterly report, 14th quarter, Jan-March 2016. Egypt: Cairo Retrieved from https://pdf.usaid.gov/pdf_docs/PA00MBKN.pdf.

Egypt Ministry of Education (MoE). (2011). Ministerial decree 369/2011. Retrieved March 28, 2020, from http://moe.gov.eg/stem/doc/STEM_target.pdf

Egypt Ministry of Education (MoE). (2012). Ministerial decree 202/2012. Retrieved 28, 2020, from http://moe.gov.eg/stem/doc/STEM_target.pdf

Egypt Ministry of Education (MoE). (2012). Ministerial decree 382/2012. Retrieved 28, 2020, from http://moe.gov.eg/stem/doc/STEM_target.pdf

Egypt Ministry of Education (MoE). (2013). Ministerial decree 308/2013. Retrieved 28, 2020, from http://moe.gov.eg/stem/doc/STEM_target.pdf

Egypt Ministry of Education (MoE). (2014). Ministerial decree 172/2014. Retrieved 28, 2020, from http://moe.gov.eg/stem/doc/STEM_target.pdf

Egypt Ministry of Education (MoE). (2014). Egypt pre-university education strategic plan: 2014-2030. Egypt: Cairo.

Egypt Ministry of Education (MoE). (2015). Ministerial decree 313/2015. Retrieved July 20, 2019, from http://portal.moe.gov.eg/AboutMinistry/Decisions/ Decisions/2015\%20-313.pdf

Egypt Vision 2030 (n.d.). Sustainable development strategy. Viewed on November 28th, 2016. Retrieved 28, 2020, from https://www.arabdevelopmentportal. com/publication/sustainable-development-strategy-sds-egypt-vision-2030

El Nagdi, M., Leammukda, F. \& Roehrig, G. (2018). Developing identities of STEM teachers at emerging STEM schools. International Journal of STEM Education, 5(36), 1-13. https://doi.org/10.1186/s40594-018-0136-1

El-deghaidy, H. (2017). STEAM methods: a case from Egypt. In J. Sickel \& S. B. Witzig (Eds.), Designing and teaching the secondary science methods course, 71-87. Sense Publishers.

Forman, J., Gubbins, E. J., Villanueva, M., Massicotte, C., Callahan, C., \& Tofel-Grehl, C. (2015). National survey of STEM high schools' curricular and instructional strategies and practices. NCSSS Journal, 20(1), 8-19.

Franzak, J. K. (2002). Developing a teacher identity: the impact of critical friends practice on the student teacher. National Council of Teachers of English, 34(4), 258-280.

Fullan, M. (2006). Change theory: a force for school improvement (Centre for Strategic Education Seminar Series Paper No. 157). Retrieved July, 20, 2019, from http://www.michaelfullan.ca/Articles_06/06_change_theory.pdf

Gough, A. (2014). STEM policy and science education: scientistic curriculum and sociopolitical silences. Cultural Studies of Science Education, 10(2), 445-458. https://doi.org/10.1007/s11422-014-9590-3

Hargreaves, A., \& Fullan, M. (2012). Professional capital: Transforming teaching in every school. New York: Teachers College Press.

Hendricks, C. (2009). Improving schools through action research: A comprehensive guide for educators. Upper Saddle River: Pearson.

Herschbach, D. (2011). The STEM initiative: Constraints and challenges. Journal of STEM Teacher Education, 48(1), 95-122.

Honey, M. Pearson, G. \& Schweingruber, H. (Eds.). (2014). STEM integration in K-12 education: Status, prospects, and an agenda for research. Washington, DC: National Academies Press.

Ibrahim, A. S. (2010). The politics of educational transfer and policymaking in Egypt. Prospects, 40(4), 499-515. Retrieved June, 15, 2018, from https://doi. org/10.1007/s11125-010-9173-3

Kingdon, J. W. (1995). Agendas, alternatives, and public policies (2nd ed.). New York: Harper Collins College Publishers.

Lave, J., \& Wenger, E. (1991). Situated learning: Legitimate peripheral participation. Cambridge: Cambridge University Press.

Ligorio, M. B. (2010). Dialogical relationship between identity and learning. Culture \& Psychology, 16(1), 93-107. https://doi.org/10.1177/ $1354067 \times 09353206$

Megahed, N. (2008). Voices of teachers in academic and vocational secondary schools in Egypt: Perceived consequences of educational reform for equity and quality. In J. Zajda, K. Biraimah, \& W. Gaudelli (Eds.), Education and social inequality in the global culture (pp. 141-154). Netherlands: Springer.
Miles, M. B., Huberman, A. M., \& Saldana, J. (2013). Qualitative data analysis: An expanded sourcebook. Thousand Oaks: Sage publications.

Provasnik, S., Malley, L., Stephens, M., Landeros, K., Perkins, R., and Tang, J.H. (2016). Highlights from TIMSS and TIMSS advanced 2015: Mathematics and science achievement of U.S. students in grades 4 and 8 and in advanced courses at the end of high school in an international context (NCES 2017002). U.S. Department of Education, National Center for Education Statistics. Washington, DC. Retrieved July, 2018, from https:/files.eric.ed.gov/fulltext/ ED570893.pdf

Reeve, E. M. (2013). Implementing science, technology, mathematics, and engineering (STEM) education in Thailand and in ASEAN. A Report Prepared for: The Institute for the Promotion of Teaching Science and Technology (IPST)

Rissmann-Joyce S. \& El Nagdi, M. (2013). A case study-Egypt's first STEM schools: lessons learned. Proceeding of the Global Summit on Education (GSE2013). Retrieved from: https://goo.gl/FVSkT8; https://doi.org/10.1007/s10798-014-92 90-z; https://doi.org/10.1007/978-3-319-93836-3

Ritz, J. M., \& Fan, S. C. (2015). STEM and technology education: international stateof-the-art. International Journal of Technology and Design Education, 25(4), 429-451. https://doi.org/10.1007/s10798-014-9290-z

Sanders, M. (2009). STEM, STEM Education, STEMmania. Focus, 19(2), 20-30.

Schutz, P. A., Hong, J., \& Francis, D. C. (Eds.). (2018). Research on teacher identity: mapping challenges and innovations. Retrieved from https://doi.org/10.1007/ 978-3-319-93836-3

National Science and Technology Council. (2013). Federal science, technology, engineering, and mathematics (STEM) education 5-year strategic plan, 143. Retrieved from http://www.whitehouse.gov/sites/default/files/microsites/ ostp/stem_stratplan_2013.pdf

Shawky. T. (2018). Some MoE officials lead a huge resistance to change. Al MasryAlyoum Portal. Retrieved from https://www.almasryalyoum.com/news/ details/1330751

Subotnik, R. F., Tai, R. H., Rickoff, R., \& Almarode, J. (2009). Specialized public high schools of science, mathematics, and technology and the STEM pipeline: What do we know now and what will we know in 5 years? Roeper Review, 32(1), 7-16. https://doi.org/10.1080/02783190903386553. https://www. researchgate.net/publication/232971888_Specialized_Public_High_Schools_ of_Science_Mathematics_and_Technology_and_the_STEM_Pipeline_What_ Do We Know Now and What Will_We Know_in_5_Years.

The Global Competitiveness Report 2017-2018 (2018). Viewed on October 5, 2018. Retrieved from https://goo.gl/2ge9sz

USAID (2016). Let girls learn: today's students, tomorrow's leaders. [Video file]. Retrieved from: https://www.youtube.com/watch?v=Zy33wq6_eK4

USAID (2019) Project fact sheet: support for STEM secondary education. Viewed on June 20,2020). Retrieved from: https://www.usaid.gov/sites/default/files/ documents/1883/USAIDEgypt_EHEdB_STEM_April_2019_EN.pdf.

Watson, C. (2006). Narratives of practice and the construction of identity in teaching. Teachers and Teaching: Theory and Practice, 12(5), 509-526.

Williams, J. P. (2011). STEM education: proceed with caution. Design and Technology Education: An International Journal, 16(1), 26-35.

World Bank. (2018). Supporting Egypt education reform. Retrieved from http:// projects.worldbank.org/P157809?lang=en

World Learning. (n.d.) Education Consortium for the Advancement of STEM in Egypt. Viewed on December 13, 2016. Retrieved from https://www.fi.edu/ education-consortium-advancement-stem-egypt-ecase

Yin, R. K. (2014). Case study research: Design and methods (5th ed.). Thousand Oaks, CA: SAGE Publications.

Zembylas, M., \& Chubbuck, S. (2015). The intersection of identity, beliefs, and politics to conceptualizing 'teacher identity. In H. Fives \& M. Gill (Eds.), International handbook of research on teachers' beliefs (pp. 173-190). New York: Routledge.

\section{Publisher's Note}

Springer Nature remains neutral with regard to jurisdictional claims in published maps and institutional affiliations. 